Article

\title{
Point-of-Decision Prompts Increase Dietary Fiber Content of Consumers' Food Choices in an Online Grocery Shopping Simulation
}

\author{
Kristina Arslain 1ㅁ, Christopher R. Gustafson $2, *$ (1) and Devin J. Rose ${ }^{1,3, * \mathbb{C}}$ \\ 1 Department of Food Science and Technology, Institute of Agriculture and Natural Resources, \\ University of Nebraska-Lincoln, Lincoln, NE 68588, USA; kristinaarslain@gmail.com \\ 2 Department of Agricultural Economics, Institute of Agriculture and Natural Resources, \\ University of Nebraska-Lincoln, Lincoln, NE 68583, USA \\ 3 Department of Agronomy \& Horticulture, Institute of Agriculture and Natural Resources, \\ University of Nebraska-Lincoln, Lincoln, NE 68583, USA \\ * Correspondence: cgustafson6@unl.edu (C.R.G.); drose3@unl.edu (D.J.R.)
}

Received: 22 September 2020; Accepted: 11 November 2020; Published: 13 November 2020

\begin{abstract}
Only 5\% of Americans consume the recommended amount of dietary fiber. In an online simulated shopping experiment, we examined whether a fiber-focused point-of-decision prompt (PDP) would influence consumers to choose food products that were higher in this important nutrient. We hypothesized that participants exposed to the dietary fiber PDP would choose products with more dietary fiber/serving than those who were not exposed to the PDP. The experiment was completed by 753 participants. Participants were randomly assigned to a condition in which they were not exposed to a PDP (the no-PDP condition), a personalized PDP, or PDP without personalization. Choices in the two PDP conditions were not significantly different. Therefore, the PDP conditions were pooled together into one condition and compared with control participants that did not receive the fiber-focused PDP. Across the three product categories, participants in the PDP condition chose products that had a greater amount of dietary fiber/serving (cereal: $22 \%$ increase; bread: $22 \%$ increase; crackers: $26 \%$ increase; $p<0.01$ ) and products that had a greater healthiness rating (cereals (odds ratio (OR): $1.45,95 \%$ confidence interval $(95 \% \mathrm{CI}):(1.10,1.92))$, bread (OR: $1.44,95 \%$ CI: $(1.09,1.91))$, and crackers (OR: $1.66,95 \%$ CI: $(1.25,2.21))$. Overall, the fiber PDP influenced participants to choose healthier products that contained greater amounts of dietary fiber.
\end{abstract}

Keywords: point-of-decision prompt; fiber; diet quality; nutrition information; food choice; online grocery store

\section{Introduction}

Poor diet, which leads to heart disease, certain types of cancer, and type 2 diabetes, is the leading risk factor for premature morbidity and chronic disability in the United States [1,2]. The health care cost of treating these chronic diseases is in excess of USD 50 billion annually [3]. Thus, strategies to promote healthier eating are imperative.

A critical, but under-appreciated, component of a healthy diet is dietary fiber [4]. Dietary fiber is an important nutrient that can aid in weight management, lower blood cholesterol, control blood sugar, maintain regularity, and increase lifespan [5]. Yet currently only 5\% of Americans consume the recommended daily intake of fiber $(14 \mathrm{~g} / 1000 \mathrm{kcal})$ [6,7]. Adult women are recommended to consume $25 \mathrm{~g}$ of fiber per day [5], but on average consume only $15.5 \mathrm{~g}$ dietary fiber/day [8]. Men are recommended to consume $38 \mathrm{~g}$ of fiber per day [5], but only consume an average of $18.4 \mathrm{~g}$ dietary fiber/day [8]. 
One way to improve dietary fiber intake is through initiatives implemented in a grocery store or supermarket environment that influence consumers to select higher-fiber products. Many food retailers in the United States and other countries already have resources in the retail environment that can facilitate healthier eating by providing nutrition information that can help consumers identify healthy food products. These resources include nutrition labeling on packaged food products, shelf labeling programs that identify the healthiness of food products (e.g., Guiding Stars in the US; Nutri-score in Europe), health and wellness information on store websites, access to educational grocery tours and registered dietitians, and in-store samples [9].

While these strategies provide the tools to make health judgments among food products, evidence of the effectiveness of these programs suggests that alternative strategies may need to be implemented to effectively promote the purchase of healthier foods. Research that has studied the provision of nutrition information in food retail settings, such as the nutrition facts label or calorie labeling on restaurant menus, finds little to no effect on average in the general population [10-12]. Due to the profusion of product options available [13], consumers may limit their attention to a subset of products [14], which may not include the healthiest options, before they begin to consider available nutrition information when making a product choice.

Many existing environmental interventions have been described as point-of-decision prompts (PDPs). PDPs are materials that are available to consumers when they are making a purchasing decision that can influence their choice and include nutrition education programs or point-of-purchase information (i.e., nutrition fact panels and shelf labels) [15-17]. More recently, literature has begun to develop around health-focused PDPs that are strategically located to influence the consumer by making health attributes salient before the narrowing of food choices within a category has begun [18]. This literature builds on research on PDPs in the context of promoting physical activity [19-21]. The use of strategically placed, simple messaging in the realm of food purchases is a recent approach to promoting healthier food choices. The existing research in this area has found that health-focused point-of-decision messages improved the healthiness of consumer grocery purchases [18,22,23]. A strategy that increases consumer motivation to buy healthy foods at the start of the food decision process may therefore improve the nutritional quality of food choices by influencing the set of products and the nutrition information the shopper considers. Consumers may be more likely to consider health in their shopping choices if they are presented with a health-focused PDP before they begin to determine which products they will consider within a category.

Although previous PDP studies have improved consumer food choice simply by reminding consumers about health and the importance of eating healthy foods [23], a PDP could be designed to target important but under-consumed nutrients. Previous research on the effect of PDPs $[18,22]$ and health primes [23] on food choices in food retail settings have examined messages promoting the consumption of a broad category of food, such as "healthy foods" or "fruits and vegetables." It is important to understand if a PDP can be used to target a specific under-consumed nutrient while also improving the general healthiness of product choices.

PDPs targeting key nutrients could provide simple educational messages to consumers as part of the prompt. For dietary fiber, in particular, many people are unaware of many of the health benefits of fiber [24]. While the majority of Americans realize that fiber helps with digestion (85\%) and weight management (72\%), far fewer realize that fiber also helps with heart health (52\%) and blood sugar control (43\%) [24]. Even fewer Americans likely realize that fiber improves the gut microbiota since this is a new benefit that members of the scientific and health communities are still working to fully document [25]. Consumers may be more motivated to increase their fiber consumption if they understand its health benefits [26].

In addition to the need to further study the use of PDPs in a grocery store environment, there is also a need to study its use in the online grocery shopping environment. Online grocery shopping is growing in popularity [27], but research on the feasibility of online nutrition promotion initiatives is limited [28]. In one poll, fewer consumers indicated looking at nutrition information when shopping 
for groceries online compared to a physical store [29], suggesting that health promotion interventions may be more critical in the online environment than in physical retail outlets. A health-focused PDP could be easily implemented in an e-commerce food shopping setting to influence consumers to make healthier food selections.

In this research, we simulate an online shopping experience to examine the effect of a PDP about the health benefits of fiber consumption on fiber content and an overall measure of healthfulness in three grain-based product categories that have significant variation in fiber levels. Our experimental design examined the influence of two slight variants of a core PDP message, compared with a no-PDP condition. The two PDPs contained the same content, but one used personal pronouns (e.g., you, your) in an effort to evoke a more personal connection to the message, while the other did not use pronouns (Figure 1). This was done because the World Health Organization reports creating a personal relevance to an issue can help make health promotion more effective [30]. We found no significant differences in outcomes in response to the two PDPs; therefore, in this paper, we have pooled the data from the two PDP conditions (termed pooled-PDP (P-PDP)) and compare choices in the presence of a PDP with choices made in the no-PDP condition. We hypothesized that participants who were presented with the dietary fiber PDP at the start of the food choice process would choose products with greater fiber content-and healthier products overall—than participants who were not presented with the PDP.

\section{Materials and Methods}

\subsection{Survey Design}

We examined how people's choices are influenced when they are exposed to a PDP in an online food choice experiment designed to mimic a person's online grocery shopping experience. The research consisted of two sections: (1) a shopping task in which participants made hypothetical food choices from three product categories: bread, cereal, and crackers; and (2) a survey. The survey included questions about product choices, typical shopping practices, and demographic variables. This survey was created in Qualtrics XM (www.qualtrics.com, 2020, SAP, Provo, UT, USA) and distributed to adults ( $\geq 19$ years old) in the United States via Amazon Mechanical Turk from 15-20 April 2020. The University of Nebraska-Lincoln Institutional Review Board (IRB) approved the research (IRB protocol \#20171017580EX). All participants provided informed consent before participating in the research.

Participants in the research were randomly assigned to a control group (no-PDP) or one of two PDP groups. The two PDP versions contained the same information about the health benefits of fiber consumption but differed slightly in the presentation of the message (Figure 1). One group saw a PDP that was written to evoke a personal connection to the messages by using personal pronouns such as "you" and "your". We refer to this condition as the personalized PDP. The message in the other group replaced the personal pronouns with impersonal articles. We refer to this condition as the PDP without personalization. Participants in the two PDP groups viewed the PDP just before beginning the shopping task, while control group participants immediately began the shopping task. 


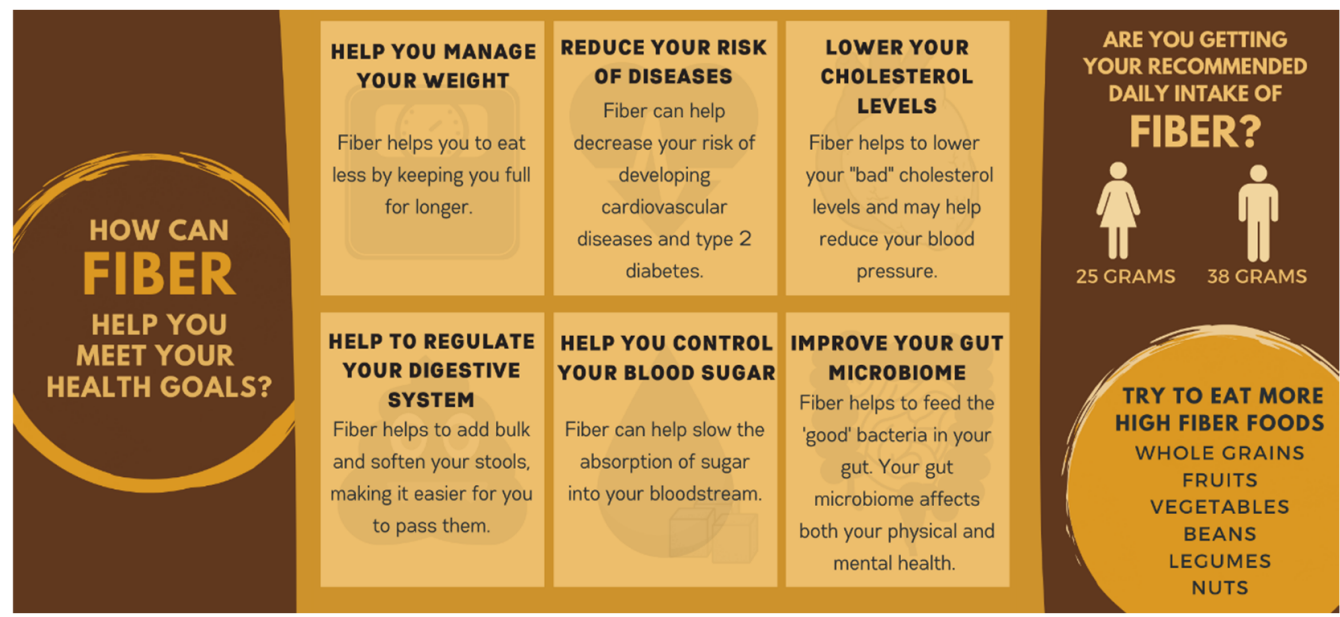

(a)

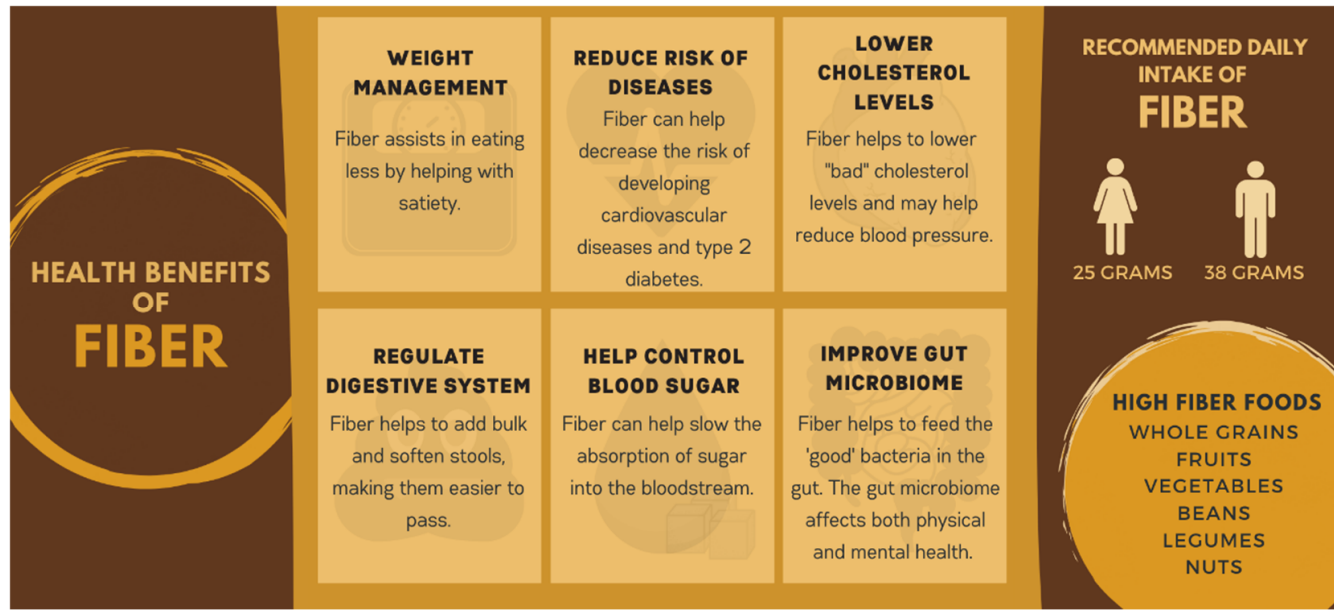

(b)

Figure 1. Point-of-decision prompts (PDP) with (a) and without (b) personalization that participants in the PDP conditions viewed before beginning the shopping task. The authors developed the figures using the graphic design website Canva (www.canva.com) [31].

In the shopping task, participants made cereal, bread, and cracker choices. Participants read an introductory text about the shopping task at the start of the survey that told them to imagine they were making real choices with real money, which has been found to reduce biases in hypothetical choices [32]. Before choosing the specific item to purchase, participants decided whether to examine all product options ( $n=33$ for each category: cereal, bread, and crackers) or to view a subset of products ( $n=11$ per subset), reflecting features in many online shopping environments that allow shoppers to easily examine a subset of products (Figure 2). The subsets categorized the products into less healthy, moderately healthy, and healthy options, using a rubric as described in Section 2.2. To avoid prompting participants to think of the subgroups according to the health of the products, the subsets were instead described by the types of products they contained. For example, the cereal sets were labeled as "Cereals such as Frosted Flakes, Froot Loops, Reese's Puffs", "Cereals such as Corn Flakes, Crispix, Special K", "Cereals such as Cheerios, Wheat Chex, Grape Nuts," and "All options".

After viewing options in each product category, participants were then able to select a product to "purchase". If a participant did not like any of the products, they had the option to decline to purchase a product for that product category. The no-product option was always listed as the last option, while all other products were presented in random order. The product options were presented in a three-column 
format with a photograph and the name of each product presented prominently. Underneath each product, the nutrient content per serving for calories, fiber, fat, sodium, and sugar, as well as the price was listed (Figure 3). After making choices in all three product categories, participants answered survey questions about their choices, typical shopping practices, and demographics.

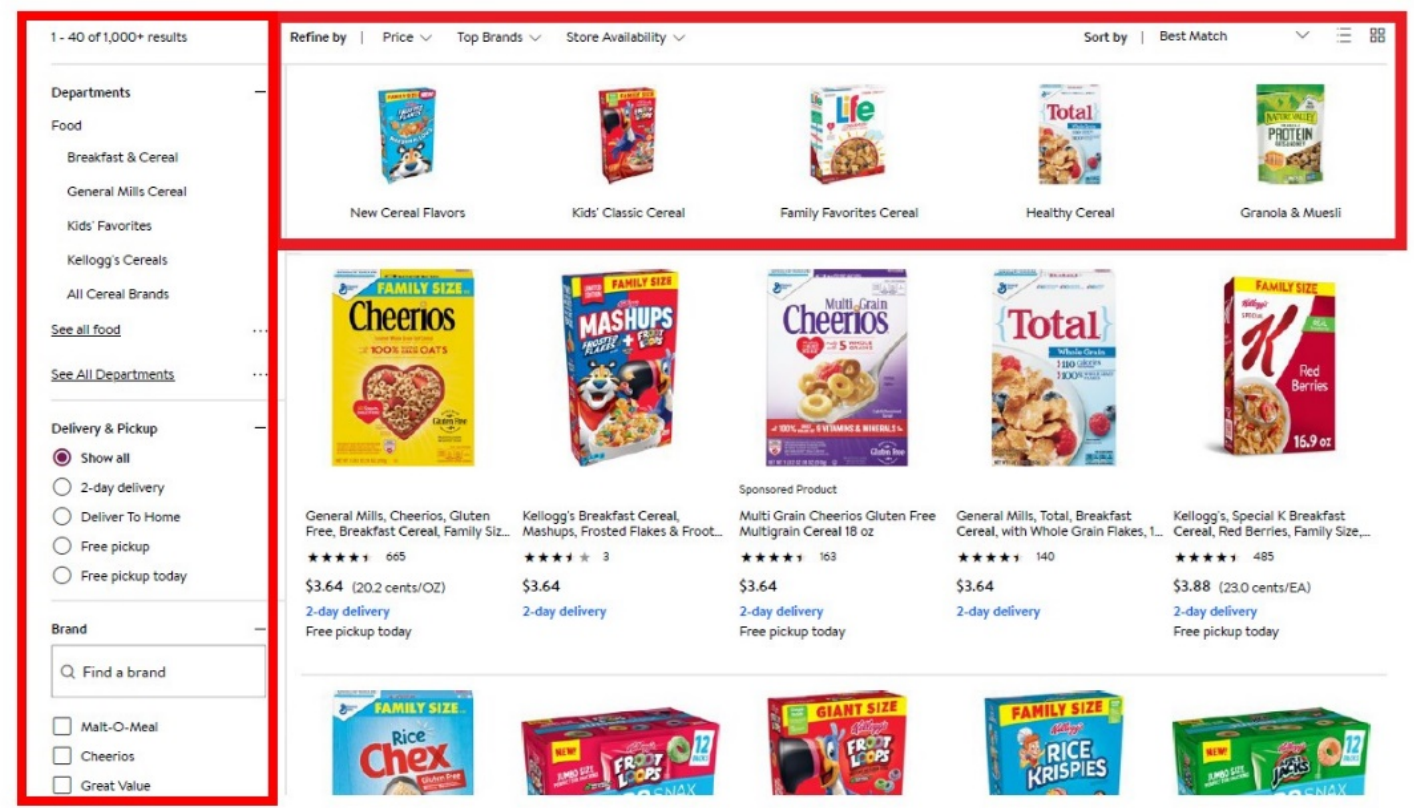

Figure 2. Screenshot of the online grocery shopping experience for a large grocery store chain. As highlighted by the red boxes, shoppers are immediately able to refine the product options and limit the choices they want to consider.

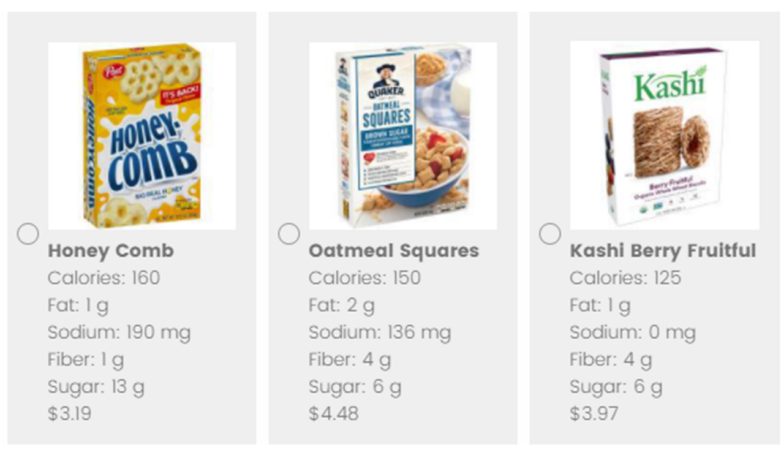

Figure 3. Image of how the cereal choice options appeared to the participant. Under each product option, the calorie, fat, sodium, fiber, and sugar content per serving along with the product price was provided.

\subsection{Allocation of Products into Healthiness Categories}

We used the Guiding Stars rubric to categorize foods into the three product subsets (less healthy, moderately healthy, and healthy options) (https://www.guidingstars.com). The Guiding Stars system grades the healthiness of products on a 0-11 point scale based on their nutrient content. Products gain points based on meeting certain thresholds for vitamins, minerals, fiber, whole grains, and omega-3 fatty acids, and lose points for surpassing amounts of saturated fat, trans fat, added sodium, added sugar, and artificial colors in a standardized 100 calorie portion. The least healthy products earn 0 points on the scale and receive zero stars, followed by one star (1-2 points), two stars (3-4 points), and finally three stars (5-11 points) for the most healthy products. We created subsets of products that received zero, one, and two or three stars in each product category (Appendix A). The two and 
three-star rated products were combined to make up the healthy subset because there were not enough three-star rated product options to create a separate category. There were three three-star-rated product options in both the cereal and bread categories and one three-star-rated product in the cracker category. As a reminder, each subset contained 11 products, making 33 product options for each of the three food categories.

\subsection{Survey Analysis}

The data were analyzed using R: The R Project for Statistical Computing [33]. Summary statistics, ordinal regression, linear regression, chi-square tests, and $t$-tests were used to analyze differences in fiber content and the healthiness of product choices (dependent variables) between PDP condition groups (independent variable). We analyzed the outcomes of the PDP separately for cereal, bread, and crackers. We considered $p<0.05$ to be statistically significant.

We first examined outcomes resulting from each PDP and the no-PDP condition, with the no-PDP condition set as the reference category. These results are reported in Appendix B. When we found no significant differences in outcomes between the two PDP conditions, we pooled data from the two PDP conditions into a single PDP condition (P-PDP) for simplicity of exposition. We report the analysis that compared outcomes in the P-PDP and no-PDP, with the no-PDP condition being the reference group. Participants that indicated they would not choose any of the products in a product category were excluded from the analyses for that specific product category for all analyses (initial disaggregated analyses and pooled analyses).

Summary statistics of the sample came from answers filled out in the survey section of the experiment. Characteristics included in our results are sex, age, household income, education, race, and whether the participant was the primary shopper. Respondents indicated their age in 5 year intervals ranging from "19-24 years old" to "65 and older". Household income was recorded in categories spanning USD 20,000 intervals, beginning with "Less than USD 20,000" and stopping at "USD 100,000 or more." Respondents selected their highest level of education completed from the options: "Less than high school"; "High school/General Education Development (GED)"; "Some college/associate degree"; "Bachelor's degree"; "Advanced degree (Master of Business Administration (M.B.A.), Doctor of Medicine (M.D.), Juris Doctor (J.D.), Master of Science (M.S.), Master of Arts (M.A.), Doctor of Philosophy (Ph.D.))"; and "Prefer not to answer." Participants were asked to select all race options that applied to them. Options included "White," "Hispanic or Latino," "Black or African American," "Native American or American Indian," "Asian or Pacific Islander", "Other", or "Prefer not to answer." Participants who selected more than one race were then merged into a "Two or more races" category. Participants were asked to answer "Yes," "Equally shared," or "No" to the question "Are you the main grocery shopper for your household?"

We examined nutrition outcomes in three ways:

1. We determined the influence of the PDP on the fiber content of participants' food choices. We calculated the mean fiber content per serving of product choices; $95 \%$ confidence intervals and $t$-tests were used to determine significance in mean difference between PDP conditions.

2. We then investigated the influence of the PDP on other nutrients (calories, fat, sodium, and sugar) in the same way we analyzed the influence of the PDP on fiber. We also calculated correlations between fiber content and the other nutrients.

3. We analyzed the influence of the PDP on the healthiness of product choices. The healthiness of products was captured by its Guiding Star rating, which ranged from zero to three stars. The Guiding Stars rating of choices was used as the dependent variable in an ordinal logistic regression model.

In the models reported in the body of the article, we have not included demographic variables. Since participants were randomized into conditions, demographic variables should not affect the impact of the PDP. As a robustness check, we conducted all analyses with the demographic variables 
included. The inclusion of demographic variables did not affect the estimated impact of the PDP but did require more participants to be dropped from the data set because of "prefer not to answer" responses. We chose to report the version without the demographic variables for simplicity and to avoid removing additional participants from the cereal, bread, and cracker models. The regression results with demographics included are provided in Appendix $C$.

\section{Results}

\subsection{Participant Demographics}

In total, 753 participants completed the experiment. There were 253 participants in the no-PDP condition, 251 in the personalized PDP condition, and 249 participants in the PDP condition without personalization (and therefore 500 in the P-PDP condition). No significant differences in demographic variables existed between no-PDP condition and the PDP conditions (Table 1). Of the 753 participants, $35.6 \%$ of the participants were female, $63.6 \%$ were male, and $0.8 \%$ preferred not to respond. Most of the participants were within the age range of $25-34$ years ( $47.4 \%$ of the sample population) or $35-44$ years (25.8\% of the sample population). A majority of respondents were the primary household shopper or shared this responsibility with other(s) in the household ( $>95 \%)$, regardless of PDP condition.

Table 1. Characteristics of the sample population ${ }^{1}$.

\begin{tabular}{|c|c|c|c|}
\hline & Total & no-PDP & P-PDP \\
\hline Variable & $\begin{array}{c}(n=753) \\
\text { Count }\end{array}$ & $\begin{array}{c}(n=253) \\
\%\end{array}$ & $\begin{array}{c}(n=500) \\
\%\end{array}$ \\
\hline \multicolumn{4}{|l|}{ Sex } \\
\hline Female & 268 & 36.0 & 35.4 \\
\hline Male & 479 & 63.6 & 63.6 \\
\hline Prefer not to answer & 6 & 0.4 & 1.0 \\
\hline \multicolumn{4}{|l|}{ Age } \\
\hline $19-24$ & 40 & 4.7 & 5.6 \\
\hline $25-34$ & 357 & 47.0 & 47.6 \\
\hline $35-44$ & 194 & 25.3 & 26.0 \\
\hline $45-54$ & 103 & 14.2 & 13.4 \\
\hline $55-64$ & 43 & 7.9 & 4.6 \\
\hline 65 and older & 12 & 0.8 & 2.0 \\
\hline Prefer not to answer & 4 & 0.0 & 0.8 \\
\hline Household Income & & & \\
\hline Less than USD 20,000 & 54 & 7.1 & 7.2 \\
\hline USD 20,000-39,999 & 146 & 17.4 & 20.4 \\
\hline USD 40,000-59,999 & 177 & 24.1 & 23.2 \\
\hline USD 60,000-79,999 & 179 & 23.3 & 24.0 \\
\hline USD 80,000-99,999 & 100 & 14.6 & 12.6 \\
\hline USD 100,000 or more & 87 & 12.6 & 11.0 \\
\hline Prefer not to answer & 10 & 0.8 & 1.6 \\
\hline \multicolumn{4}{|l|}{ Education } \\
\hline Less than high school & 2 & 0.4 & 0.2 \\
\hline High school/G.E.D. & 80 & 10.3 & 10.8 \\
\hline Associate's degree or some college & 124 & 18.6 & 15.4 \\
\hline Bachelor's degree & 400 & 49.0 & 55.2 \\
\hline Advanced degree (master's level or higher) & 143 & 21.7 & 17.6 \\
\hline Prefer not to answer & 4 & 0.0 & 0.8 \\
\hline \multicolumn{4}{|l|}{ Race } \\
\hline White & 528 & 71.9 & 69.2 \\
\hline Hispanic or Latino & 37 & 4.3 & 5.2 \\
\hline Black or African American & 104 & 14.6 & 13.4 \\
\hline Native American or American Indian & 5 & 0.4 & 0.8 \\
\hline Asian or Pacific Islander & 35 & 5.1 & 4.4 \\
\hline Other & 1 & 0.0 & 0.2 \\
\hline Two or more & 38 & 3.6 & 5.8 \\
\hline Prefer not to answer & 5 & 0 & 1.0 \\
\hline \multicolumn{4}{|l|}{ Primary Shopper } \\
\hline Yes & 514 & 67.6 & 68.6 \\
\hline Equally shared & 207 & 28.5 & 27.0 \\
\hline No & 32 & 4.0 & 4.4 \\
\hline
\end{tabular}

1 There were no significant differences between conditions (chi-squared test). Notes: no-PDP = participants were not exposed to a prompt; P-PDP = pooled prompt condition; G.E.D. = General Education Development. 


\subsection{PDP Effect on Fiber Content of Choices}

We first examined how the PDP influenced the fiber content among participants' cereal, bread, and cracker choices. In all product categories, the participants in the PDP condition selected products with significantly more fiber per serving (Figure 4). For cereals, subjects that viewed the PDP before making their product choice selected products with $0.71 \mathrm{~g}$ more dietary fiber/serving $(p=0.002)$ than those in the no-PDP condition (a $22 \%$ increase). For the bread category, participants in the P-PDP condition chose bread products with an average of $0.46 \mathrm{~g}$ more dietary fiber/serving $(p=0.001)$ than those in the no-PDP condition (a $22 \%$ increase). Crackers chosen by participants in the P-PDP condition had an average of $0.43 \mathrm{~g}$ more dietary fiber/serving $(p=0.002)$ than those in the no-PDP condition (a $26 \%$ increase).

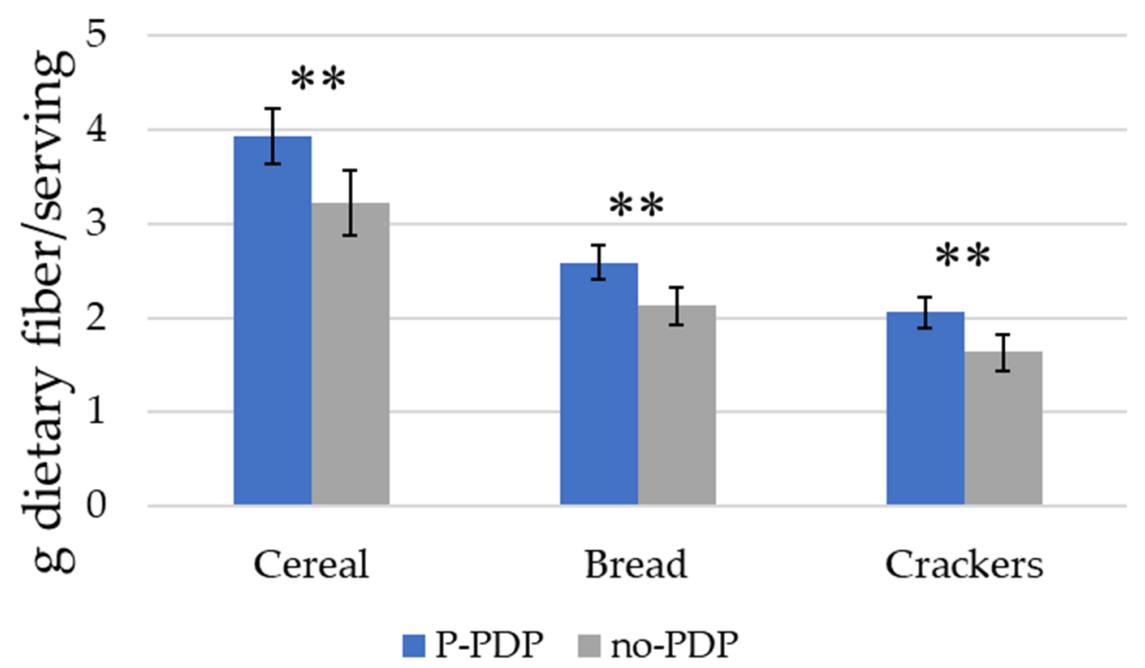

Figure 4. The dietary fiber content of product choices made by participants in P-PDP and no-PDP conditions. Error bars represent the $95 \%$ confidence interval around the mean. The analyses included only those subjects that made a product choice; 24 (3.2\%), 19 (2.5\%), and $18(2.4 \%)$ participants who had selected "none of these" in the cereal, bread, and cracker models were omitted prior to the analyses. This left $n=729$ cereal choices, $n=734$ bread choices, and $n=735$ cracker choices. ${ }^{* *} p<0.01$. Notes: no-PDP $=$ participants were not exposed to a prompt); P-PDP $=$ pooled prompt condition.

\subsection{PDP Effect on Other Nutrient Content of Choices}

We next examined the average calorie, fat, sodium, and sugar content of products chosen in the P-PDP and no-PDP groups (Figure 5). For cereals, subjects who viewed the PDP before making their product choice selected products with $0.76 \mathrm{~g}$ less sugar/serving $(p=0.033)$ than those in the no-PDP condition (a 9\% decrease). For the cracker category, participants in the P-PDP condition chose crackers with an average of 4.95 fewer calories/serving $(p=0.002)$ than those in the no-PDP condition (a $4 \%$ decrease). Crackers chosen by participants in the P-PDP condition had an average of $0.63 \mathrm{~g}$ less fat $/$ serving $(p=0.001)$ than those in the no-PDP condition (an 11\% decrease).

After determining the nutrient differences between products chosen by participants in the P-PDP condition and the no-PDP condition, we calculated correlations between dietary fiber content and the other nutrients in all products included in the research (Table 2). The dietary fiber content per serving in cereals was negatively correlated with the calorie, sodium, and sugar contents. The dietary fiber content in crackers was negatively correlated with all nutrients investigated. 


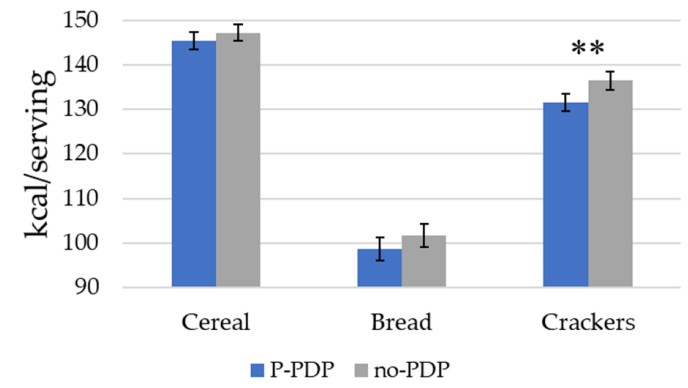

(a)

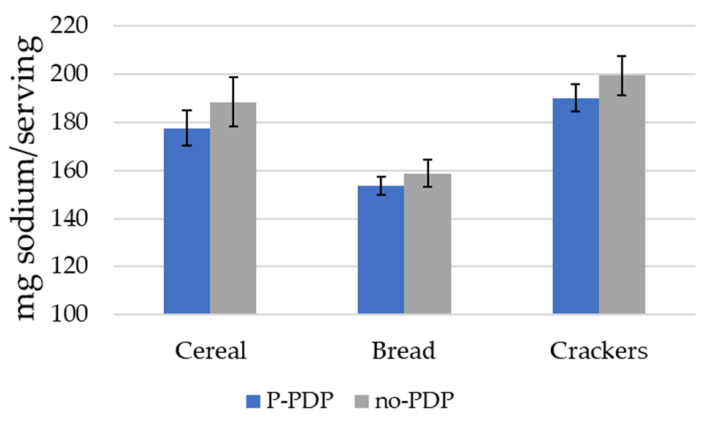

(c)

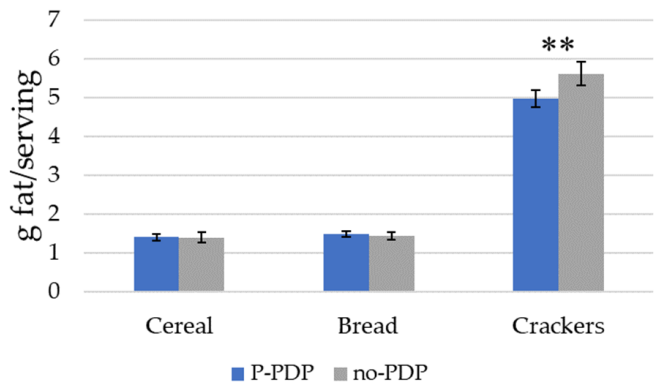

(b)

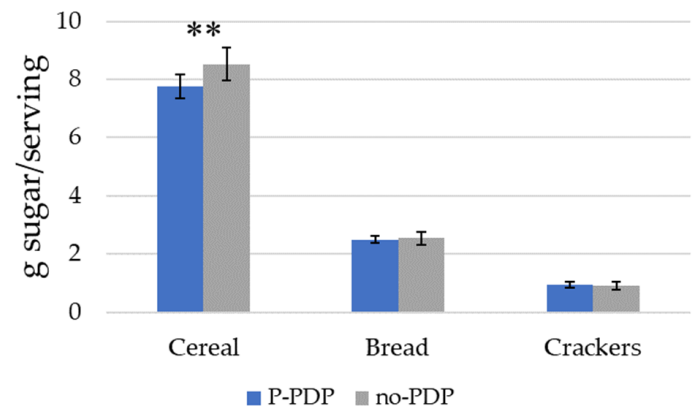

(d)

Figure 5. Mean nutrient content of products by participants in the P-PDP and no-PDP conditions. (a) Calories; (b) fat; (c) sodium; (d) sugar. Error bars represent the 95\% confidence interval around the mean; $p$-values compare significant differences between the mean nutrition content of product choices made by the P-PDP and the no-PDP condition ( $t$-test). ${ }^{* *} p<0.01$.

Table 2. Correlations between the fiber content and the content of other nutrients per serving in the cereal, bread, and cracker products included in the research $(n=33$ per category).

\begin{tabular}{ccccc}
\hline Category & Calories & Fat & Sodium & Sugar \\
\hline Cereal & $-0.61^{* * *}$ & 0.09 & $-0.39^{*}$ & $-0.49^{* *}$ \\
Bread & 0.08 & 0.16 & 0.06 & 0.29 \\
Crackers & $-0.88^{* * *}$ & $-0.70^{* * *}$ & $-0.55^{* * *}$ & $-0.40^{*}$ \\
\hline \multicolumn{5}{c}{$p<0.05,{ }^{* *} p<0.011^{* * *} p<0.001}$.
\end{tabular}

\subsection{PDP Effect on Healthiness of Choices}

Next, we examined how exposure to the PDP influenced the overall healthiness of participants' product choices for cereal, bread, and crackers to determine how a fiber-focused PDP impacted the general nutritional quality of food choices. Odds ratios were used to report the effect of the P-PDP on the Guiding Star rating of products selected (Figure 6). Exposure to the PDP led participants to choose a product with a higher Guiding Star rating for cereals (odds ratio (OR): 1.45, 95\% CI: 1.10, 1.92), bread (OR: 1.44, 95\% CI: 1.09, 1.91), and crackers (OR: 1.66, 95\% CI: 1.25, 2.21). 


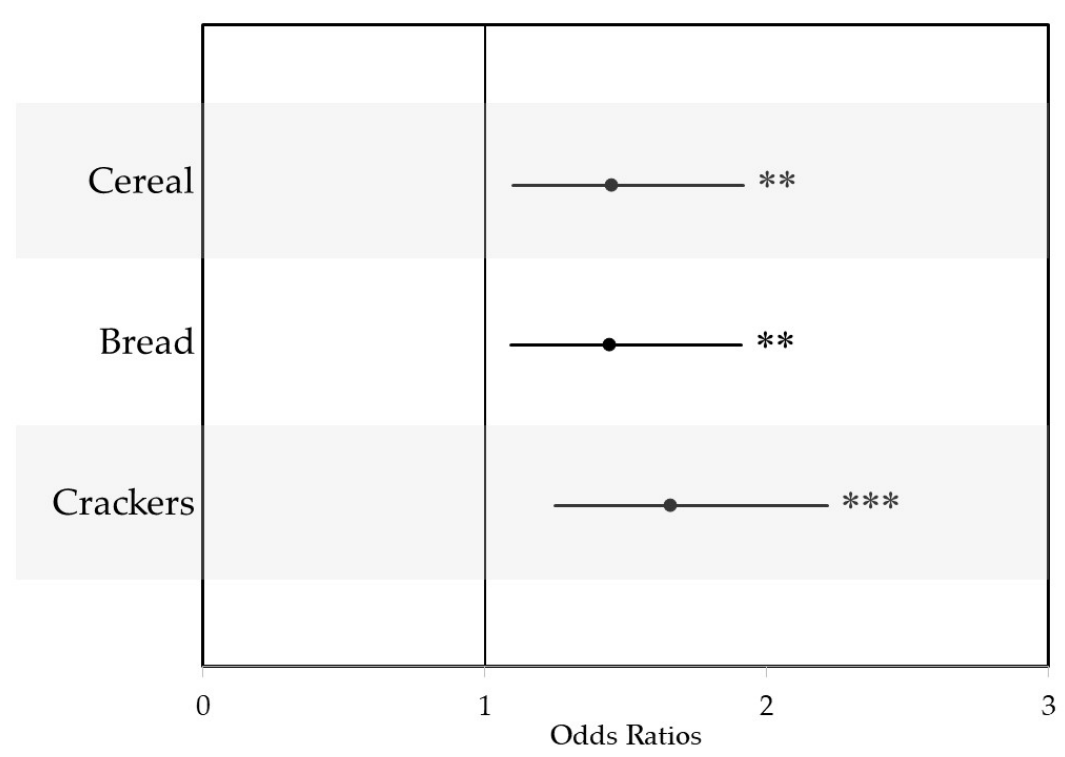

Figure 6. Odds ratios for the influence of a PDP on the healthiness of choices, represented by a product's Guiding Stars rating with $95 \%$ confidence intervals. ${ }^{* *} p<0.01,{ }^{* * *} p<0.001$.

\section{Discussion}

Our research corroborates earlier findings that PDPs increase the nutritional quality of food choices [18], but we additionally find that a PDP highlighting the benefits of dietary fiber-an under-consumed nutrient-improves the healthiness of cereal, bread, and cracker choices in a grocery store environment by increasing the amount of dietary fiber/serving in products chosen by participants in the prompt condition. In all three product categories, participants in the P-PDP condition chose products that contained higher fiber density, but were also more likely to select products with higher Guiding Star ratings, suggesting that, in addition to successfully targeting fiber content, the prompt increased the overall nutritional quality of choices compared to choices made by participants in the no-PDP condition. Our correlation analysis suggests that the higher nutritional quality is due both to higher dietary fiber, which contributes to nutritional quality, but also to correlations between fiber and other nutritional attributes that improve the overall nutritional profile of the foods.

The PDP led to fiber increases of $0.43-0.71 \mathrm{~g}$ dietary fiber/serving in each of the three product categories, resulting in a total difference of approximately $1.5 \mathrm{~g}$ of dietary fiber/serving across the three food categories. Given that the average fiber intake in the US is $16.2 \mathrm{~g} /$ day [8], consumption of one serving of products from each of these categories per day would lead to a $10 \%$ increase in total fiber consumption. Currently, the majority of consumer grain-based fiber consumption comes from the high consumption of low fiber foods, so successfully encouraging consumers to choose products with higher fiber content could yield marked increases in consumption of dietary fiber. Participants in the P-PDP condition also selected generally healthier products, as represented by the Guiding Star rating of the products chosen.

Inattentiveness to long-term goals, such as health during decision-making, has been documented in extensive literature on executive function $[34,35]$. Low executive function is associated with the inability to successfully ignore short-term temptations—such as taste-over long-term rewards that have less of an immediate benefit-such as health [34]. PDPs may work better than nutrition information at reminding consumers of goals for their long-term health. Laboratory studies that simultaneously capture behavioral and neurocognitive data provide evidence on how PDPs may remind one of their long-term health goals. People experience different neural activations when prompted to think about health before making food choices compared to when they are prompted to think of taste or not prompted at all [18]. The neural activation of health-primed individuals resembled dieters who successfully exerted self-control during food choice in an earlier study [36]. Behaviorally, 
health-primed individuals placed greater value on health attributes and, as a result, were more likely to choose a healthy item [37]. PDPs may be able to help consumers incorporate their long-term goals to balance short-term rewards by recruiting neural systems that are necessary for self-control. Future research should investigate mechanisms by which the PDP affects decision making.

It is important to remind consumers of long-term health goals at the start of their food decision process. With so many product choices within a category, consumers may not consider nutrition information available for products until they have already narrowed their choices down to a subset of choices [14]. Once consumers begin to compare their subset of choices, they may get distracted from the nutrition information by the visuals of the packages [38]. Health-focused PDPs may disrupt both of these processes, leading consumers to consider a broader array of products and reminding them to consider nutrition information. Reminding consumers at the start of their food choice process may better encourage shoppers to consider nutrition in their product selection.

Simulating the shopping experience online directly relates our findings to online grocery shopping experiences. Our research is particularly relevant for the growing segment of the population purchasing groceries online or through an app. An increasing number of consumers have begun to do their grocery shopping online. As of 2019, over 36\% of Americans reported that they purchased groceries online [27], and more people have reported using online grocery shopping during the COVID-19 pandemic [39]. Before the epidemic, the Food Marketing Institute and Nielsen predicted that nearly three-fourths of consumers would purchase groceries online by 2024 [40]. With the transition from brick-and-mortar to e-commerce grocery shopping, policymakers, researchers, and public health professionals must understand how to encourage healthier food choices in an online grocery shopping platform. The findings in our study support presenting a health PDP on the computer screen before consumers begin to fill their online grocery cart. However, we view our results as being relevant beyond the online shopping environment. Previous research on PDPs and primes was conducted in retail food stores [6,9], and many consumers continue to predominantly purchase food in-store. While previous PDPs have been physically displayed in-store [6], the rise of "smart" devices that are always with consumers, such as phones and watches, present additional—and customizable—opportunities to prompt consumers when they are in the retail food outlet.

An interesting note about our findings is that the data were collected during the midst of the COVID-19 pandemic. The COVID-19 pandemic has led to increased stress in individuals and an economic downturn. During this time, a third of Americans reported experiencing a high level of psychological distress [41] and purchases of less healthy foods increased [42]. Historically, people consume more unhealthy foods when under these types of pressures [42]. Despite consumers likely feeling stressed, our study still found that the PDP encouraged healthier choices. Our PDP might have been more influential if the data had not been collected during the COVID-19 pandemic. In future work, it may be interesting to collect data using this survey design once the COVID-19 pandemic has passed. This would allow us to examine changes in the effect of the PDP when consumers experience higher than average levels of stress.

A limitation of this study is that product choices were hypothetical. By making hypothetical choices, participants may not have invested as much effort in considering product options or reading product nutrition information. We attempted to address this potential bias by prompting participants to make choices as though they would be actually buying the products, and facing the same budget constraints they do in real life, which has been found to reduce hypothetical bias [32]. While we do not report these data in the paper, analyses show that participants responded to prices in our experiment and were less likely to select higher priced items, suggesting that we were able to mitigate biases related to hypothetical choices.

In conclusion, our data show that participants who were presented a PDP about the health benefits of fiber made healthier product choices within the cereal, bread, and cracker categories by selecting products with higher fiber. This study adds to the burgeoning literature about the use of health PDPs to promote healthy food choices. 
Author Contributions: Conceptualization, K.A., C.R.G. and D.J.R.; methodology, K.A., C.R.G. and D.J.R.; formal analysis, K.A.; investigation, K.A. and C.R.G.; data curation, K.A. and C.R.G.; writing-original draft preparation, K.A.; writing-review and editing, K.A., C.R.G. and D.J.R.; visualization, K.A., D.J.R. and C.R.G.; supervision, C.R.G. and D.J.R.; project administration, C.R.G. and D.J.R.; funding acquisition, C.R.G. and D.J.R. All authors have read and agreed to the published version of the manuscript.

Funding: This project is based on research that was supported by the University of Nebraska-Lincoln Agricultural Research Division Wheat Innovation Fund and was partially supported by the Nebraska Agricultural Experiment Station with funding from the Hatch Act (Accession Number 1011290) through the USDA National Institute of Food and Agriculture. The funder had no role in the research or decision to publish.

Conflicts of Interest: The authors declare no conflict of interest.

\section{Appendix A}

Table A1. Nutrition content of product choices within Guiding Star ratings ${ }^{1}$.

\begin{tabular}{|c|c|c|c|c|c|c|c|c|c|c|c|c|c|c|c|c|}
\hline & \multirow[t]{2}{*}{$n$} & \multicolumn{3}{|c|}{$\begin{array}{c}\text { Fiber } \\
\text { (g/Serving) }\end{array}$} & \multicolumn{3}{|c|}{$\begin{array}{c}\text { Calories } \\
\text { (kcal/Serving) }\end{array}$} & \multicolumn{3}{|c|}{$\begin{array}{c}\text { Fat } \\
\text { (g/Serving) }\end{array}$} & \multicolumn{3}{|c|}{$\begin{array}{c}\text { Sodium } \\
\text { (mg/Serving) }\end{array}$} & \multicolumn{3}{|c|}{$\begin{array}{c}\text { Sugar } \\
\text { (g/Serving) }\end{array}$} \\
\hline & & Mean & Min & $\operatorname{Max}$ & Mean & Min & Max & Mean & Min & Max & Mean & Min & Max & Mean & Min & Max \\
\hline \multicolumn{17}{|l|}{ Cereal } \\
\hline 0 Stars & 11 & 1.4 & 0 & 4 & 154 & 140 & 170 & 1.8 & 0 & 4.5 & 204 & 140 & 270 & 13.2 & 12 & 16 \\
\hline 1 Stars & 11 & 2.6 & 0 & 4 & 152 & 140 & 160 & 1.1 & 0 & 2.5 & 241 & 136 & 300 & 8.9 & 4 & 12 \\
\hline 2 Stars & 8 & 5.3 & 4 & 12 & 145 & 120 & 200 & 1.4 & 0.5 & 2.5 & 137 & 0 & 267 & 6.8 & 2 & 13 \\
\hline 3 Stars & 3 & 8.0 & 5 & 14 & 123 & 90 & 140 & 1.2 & 1 & 1.5 & 111 & 0 & 193 & 1.0 & 0 & 3 \\
\hline \multicolumn{17}{|l|}{ Bread } \\
\hline 0 Stars & 11 & 1.0 & 0.5 & 2 & 121 & 70 & 160 & 1.5 & 0.5 & 5 & 196 & 120 & 295 & 3.0 & 0 & 5.5 \\
\hline 1 Stars & 11 & 1.9 & 0 & 3.5 & 79 & 45 & 125 & 1.1 & 0.5 & 2 & 126 & 85 & 180 & 1.5 & 0.5 & 3.5 \\
\hline 2 Stars & 8 & 3.9 & 1.5 & 8 & 92 & 60 & 120 & 1.8 & 1 & 3 & 153 & 115 & 220 & 2.8 & 0.5 & 5 \\
\hline 3 Stars & 3 & 3.7 & 3 & 4 & 93 & 50 & 130 & 2.0 & 1 & 2.5 & 117 & 85 & 135 & 1.5 & 0.5 & 3 \\
\hline \multicolumn{17}{|l|}{ Crackers } \\
\hline 0 Stars & 11 & 0.4 & 0 & 1 & 147 & 140 & 150 & 7.3 & 5 & 9.5 & 259 & 210 & 380 & 1.5 & 0 & 4 \\
\hline 1 Stars & 11 & 1.8 & 0 & 3 & 132 & 120 & 140 & 3.9 & 1.5 & 5.5 & 147 & 85 & 250 & 1.1 & 0 & 3 \\
\hline 2 Stars & 10 & 3.5 & 1 & 7 & 121 & 69 & 150 & 4.0 & 0 & 8 & 172 & 115 & 270 & 0.1 & 0 & 0.5 \\
\hline 3 Stars & 1 & 7.0 & 7 & 7 & 67 & 67 & 67 & 0.0 & 0 & 0 & 117 & 117 & 117 & 0.0 & 0 & 0 \\
\hline
\end{tabular}

${ }^{1} 0$ stars = least healthy; 1 star = moderately healthy; 2 or 3 stars = most healthy.

\section{Appendix B}

Table A2. Estimate and 95\% confidence interval around the estimate for nutrient content of products by participants in the personalized PDP and PDP without personalization compared with the no-PDP condition ${ }^{1}$.

\begin{tabular}{|c|c|c|c|c|c|c|c|c|}
\hline \multirow{2}{*}{ Nutrients } & \multicolumn{4}{|c|}{ Personalized PDP } & \multicolumn{4}{|c|}{ PDP without Personalization } \\
\hline & Estimate & CI Low & CI High & & Estimate & CI Low & CI High & \\
\hline Fiber & & & & & & & & \\
\hline Cereal & 0.64 & 0.10 & 1.19 & $*$ & 0.78 & 0.23 & 1.33 & ** \\
\hline Bread & 0.54 & 0.20 & 0.88 & $* *$ & 0.37 & 0.03 & 0.71 & * \\
\hline Crackers & 0.39 & 0.07 & 0.72 & $*$ & 0.47 & 0.14 & 0.79 & ** \\
\hline Calories & & & & & & & & \\
\hline Cereal & -0.34 & -3.83 & 3.15 & & -3.28 & -6.78 & 0.22 & \\
\hline Bread & -2.55 & -7.74 & 2.64 & & -3.57 & -8.81 & 1.68 & \\
\hline $\begin{array}{c}\text { Crackers } \\
\text { Fat }\end{array}$ & -4.65 & -8.48 & -0.81 & * & -5.25 & -9.07 & -1.42 & ** \\
\hline Cereal & 0.03 & -0.15 & 0.21 & & 0.00 & -0.18 & 0.18 & \\
\hline Bread & 0.02 & -0.13 & 0.16 & & 0.11 & -0.03 & 0.26 & \\
\hline Crackers & -0.56 & -1.01 & -0.12 & $*$ & -0.70 & -1.14 & -0.26 & $* *$ \\
\hline Sodium & & & & & & & & \\
\hline Cereal & 0.64 & 0.10 & 1.19 & $*$ & 0.78 & 0.23 & 1.33 & $* *$ \\
\hline Bread & -5.27 & -12.76 & 2.23 & & -5.10 & -12.67 & 2.47 & \\
\hline $\begin{array}{c}\text { Crackers } \\
\text { Sugar }\end{array}$ & -9.66 & -20.84 & 1.52 & & -8.99 & -20.13 & 2.16 & \\
\hline Cereal & -0.89 & -1.70 & -0.07 & $*$ & -0.64 & -1.46 & 0.17 & \\
\hline Bread & 0.06 & -0.20 & 0.31 & & -0.13 & -0.39 & 0.13 & \\
\hline Crackers & 0.00 & -0.20 & 0.21 & & 0.00 & -0.20 & 0.21 & \\
\hline
\end{tabular}

${ }^{1}$ Estimate results from linear regression models comparing nutrient content of choices between the personalized PDP, no personalization PDP, and no-PDP conditions. The no-PDP condition was used as the reference group. There were 24, 19, and 18 participants removed from the cereal, bread, and cracker models, respectively. ${ }^{*} p<0.05$, $* * p<0.01$. 
Table A3. Odds ratios (OR) and 95\% confidence intervals (CI) for the influence of the personalized PDP, PDP without personalization, and no-PDP on the healthiness of participants' choices ${ }^{1}$.

\begin{tabular}{ccccccccc}
\hline & \multicolumn{3}{c}{ Personalized PDP } & \multicolumn{4}{c}{ PDP w/o Personalization } \\
Category & Estimate & CI Low & CI High & & Estimate & CI Low & CI High & \\
\hline Cereal & 1.46 & 1.07 & 2.01 & $*$ & 1.44 & 1.04 & 1.99 & $*$ \\
Bread & 1.44 & 1.05 & 1.97 & $*$ & 1.45 & 1.05 & 2.02 & $*$ \\
Crackers & 1.52 & 1.10 & 2.12 & $*$ & 1.81 & 1.30 & 2.51 & $* * *$ \\
\hline
\end{tabular}

${ }^{1}$ Healthiness measured in terms of Guiding Star rating. The no-PDP condition was set as the reference category. There were 24, 19, and 18 participants removed from the cereal, bread, and cracker models, respectively. ${ }^{*} p<0.05$, *** $p<0.001$.

Table A4. Mean and 95\% confidence interval around the mean for nutrient content of products by participants in the Personalized PDP and PDP without personalization conditions ${ }^{1}$.

\begin{tabular}{|c|c|c|c|c|c|c|c|}
\hline \multirow[b]{2}{*}{ Nutrients } & \multicolumn{3}{|c|}{ Personalized PDP } & \multicolumn{3}{|c|}{ PDP w/o Personalization } & \multirow[b]{2}{*}{$p$-Value } \\
\hline & Average & CI Low & CI High & Average & CI Low & CI High & \\
\hline \multicolumn{8}{|c|}{ Fiber (g/serving) } \\
\hline Cereal & 3.86 & 3.48 & 4.25 & 4.00 & 3.70 & 4.29 & 0.641 \\
\hline Bread & 2.67 & 2.40 & 2.94 & 2.50 & 2.33 & 2.67 & 0.351 \\
\hline Crackers & 2.02 & 1.77 & 2.26 & 2.09 & 1.93 & 2.26 & 0.657 \\
\hline \multicolumn{8}{|c|}{ Calories (kcal/serving) } \\
\hline Cereal & 146.91 & 144.20 & 149.62 & 143.97 & 142.14 & 145.80 & 0.127 \\
\hline Bread & 99.20 & 95.65 & 102.74 & 98.18 & 95.54 & 100.82 & 0.699 \\
\hline Crackers & 131.86 & 128.97 & 134.76 & 131.27 & 129.31 & 133.22 & 0.771 \\
\hline \multicolumn{8}{|c|}{ Fat $(\mathrm{g} /$ serving $)$} \\
\hline Cereal & 1.42 & 1.30 & 1.55 & 1.40 & 1.31 & 1.48 & 0.775 \\
\hline Bread & 1.45 & 1.35 & 1.55 & 1.55 & 1.47 & 1.62 & 0.205 \\
\hline Crackers & 5.04 & 4.73 & 5.36 & 4.91 & 4.69 & 5.13 & 0.552 \\
\hline \multicolumn{8}{|c|}{ Sodium (mg/serving) } \\
\hline Cereal & 180.42 & 170.43 & 190.40 & 174.75 & 167.05 & 182.44 & 0.455 \\
\hline Bread & 153.53 & 148.50 & 158.57 & 153.70 & 149.88 & 157.52 & 0.964 \\
\hline Crackers & 189.78 & 182.06 & 197.50 & 190.46 & 184.91 & 196.01 & 0.905 \\
\hline \multicolumn{8}{|c|}{ Sugar (g/serving) } \\
\hline Cereal & 7.65 & 7.09 & 8.21 & 7.89 & 7.47 & 8.31 & 0.562 \\
\hline Bread & 2.60 & 2.41 & 2.78 & 2.41 & 2.27 & 2.54 & 0.157 \\
\hline Crackers & 0.93 & 0.78 & 1.08 & 0.93 & 0.82 & 1.03 & 0.991 \\
\hline
\end{tabular}

${ }^{1} p$-values compare significant differences between the mean nutrition content of product choices made by the Personalized PDP, PDP without personalization condition (t-test).

Table A5. Odds ratios (OR) and 95\% confidence intervals (CI) for the influence of a Personalized PDP (vs. PDP without Personalization) on the healthiness of participants' choices ${ }^{1}$.

\begin{tabular}{cccc}
\hline Category & \multicolumn{3}{c}{ Personalized PDP (vs. PDP w/o Personalization) } \\
Odds Ratio (OR) & CI Low & CI High \\
\hline Cereal & 1.02 & 0.74 & 1.40 \\
Bread & 0.99 & 0.72 & 1.36 \\
Crackers & 0.84 & 0.61 & 1.17 \\
\hline
\end{tabular}

\footnotetext{
${ }^{1}$ Healthiness measured in terms of Guiding Star rating. There were 18, 12, and 13 participants removed from the
} cereal, bread, and cracker models, respectively. 


\section{Appendix C}

Table A6. Odds ratios (OR) and 95\% confidence intervals (CI) for the influence of the PDP on the healthiness of participants' choices with demographics ${ }^{1}$.

\begin{tabular}{ccccc}
\hline & \multicolumn{4}{c}{ P-PDP (vs. no-PDP) } \\
Category & OR & CI Low & CI High & \\
\hline Cereal & 1.49 & 1.13 & 1.98 & $* *$ \\
Bread & 1.50 & 1.13 & 1.99 & $* *$ \\
Crackers & 1.72 & 1.28 & 2.30 & $* * *$ \\
\hline
\end{tabular}

${ }^{1}$ Healthiness measured in terms of Guiding Star rating. Demographic variables (sex, age, years of education, and household income) were included in the regression model. There were 34, 28, and 28 participants removed from the cereal, bread, and cracker models, respectively. ${ }^{* *} p<0.01,{ }^{* * *} p<0.001$.

\section{References}

1. Murray, C.J.L.; Abraham, J.; Ali, M.K.; Alvarado, M.; Atkinson, C.; Baddour, L.M.; Bartels, D.H.; Benjamin, E.J.; Bhalla, K.; Birbeck, G.; et al. The State of US Health, 1990-2010. JAMA 2013, 310, 591-606. [CrossRef] [PubMed]

2. Murphy, S.L.; Kochanek, K.D.; Xu, J.; Arias, E. Mortality in the United States, 2014. NCH Data Brief. 2015, $229,8$.

3. Jardim, T.V.; Mozaffarian, D.; Abrahams-Gessel, S.; Sy, S.; Lee, Y.; Liu, J.; Huang, Y.; Rehm, C.; Wilde, P.; Micha, R.; et al. Cardiometabolic disease costs associated with suboptimal diet in the United States: A cost analysis based on a microsimulation model. PLoS Med. 2019, 16, e1002981. [CrossRef] [PubMed]

4. Hoy, M.K.; Goldman, J. Dietary fiber intake of the U.S. population: What We Eat in America, NHANES 2009-2010. Food Surv. Res. Group Diet. Data Brief. 2014, 12, 6.

5. Mayo Clinic. Dietary Fiber: Essential for a Healthy Diet. Available online: https://www.mayoclinic.org/ healthy-lifestyle/nutrition-and-healthy-eating/in-depth/fiber/art-20043983 (accessed on 5 July 2020).

6. Hyland, J. Fast Fiber Facts: What it Is and How to Get Enough. US News \& World Report. 2018. Available online: https://health.usnews.com/health-care/for-better/articles/2018-08-22/fast-fiber-facts-what-it-is-andhow-to-get-enough (accessed on 22 June 2020).

7. Kranz, S.; Dodd, K.W.; Juan, W.Y.; Johnson, L.K.; Jahns, L. Whole Grains Contribute Only a Small Proportion of Dietary Fiber to the U.S. Diet. Nutrients 2017, 9, 153. [CrossRef]

8. U.S. Department of Agriculture, Agricultural Research Service. Nutrient Intakes from Food and Beverages: Mean Amounts Consumed per Individual, by Gender and Age. 2020. Available online: https://www.ars. usda.gov/ARSUserFiles/80400530/pdf/1718/Table_1_NIN_GEN_17.pdf (accessed on 11 September 2020).

9. Nikolova, H.D.; Inman, J. Healthy Choice: The Effect of Simplified Point-of-Sale Nutritional Information on Consumer Food Choice Behavior. J. Mark. Res. 2015, 52, 817-835. [CrossRef]

10. Cantor, J.; Torres, A.; Abrams, C.; Elbel, B. Five Years Later: Awareness of New York City's Calorie Labels Declined, With No Changes in Calories Purchased. Health Aff. 2015, 34, 1893-1900. [CrossRef]

11. Elbel, B.; Kersh, R.; Brescoll, V.L.; Dixon, L.B. Calorie Labeling And Food Choices: A First Look At The Effects On Low-Income People In New York City. Health Aff. 2009, 28, w1110-w1121. [CrossRef]

12. Rawson, D.; Janes, I.; Jordan, K. Pilot Study to Investigate the Potential of Eye Tracking as a Technique for FSA Food Labelling Behaviour Research. 2008. Available online: https://www.fcrn.org.uk/sites/default/files/ Food_Labelling_and_eyetracking.pdf (accessed on 17 June 2020).

13. Nielsen Global Connect. It's Not Just About the Shelf: Creating the Ideal In-Store Experience. Available online: https://www.nielsen.com/us/en/insights/article/2016/its-not-just-about-the-shelf-creating-the-idealin-store-experience (accessed on 17 June 2020).

14. Masatlioglu, Y.; Nakajima, D.; Ozbay, E.Y. Revealed Attention. Am. Econ. Rev. 2012, 102, $2183-2205$. [CrossRef]

15. Milliron, B.J.; Woolf, K.; Appelhans, B.M. A Point-of-Purchase Intervention Featuring in Person Supermarket Education Affects Healthful Food Purchases. J. Nutr. Educ. Behav. 2012, 44, 225-232. [CrossRef] 
16. Hunt, M.K.; Lefebvre, R.C.; Hixson, M.L.; Banspach, S.W.; Assaf, A.R.; Carleton, R.A. Pawtucket Heart Health Program point-of-purchase nutrition education program in supermarkets. AJPH 1990, 80, 730-732. [CrossRef] [PubMed]

17. Mayer, J.A.; Dubbert, P.M.; Elder, J.P. Promoting Nutrition at the Point of Choice: A Review. Health Educ. Q. 1989, 16, 31-43. [CrossRef] [PubMed]

18. Gustafson, C.R.; Kent, R.; Prate, M.R. Retail-based healthy food point-of-decision prompts (PDPs) increase healthy food choices in a rural, low-income, minority community. PLoS ONE 2018, 13, e0207792. [CrossRef] [PubMed]

19. Russell, W.D.; Dzewaltowski, D.A.; Ryan, G.J. The effectiveness of a point-of-decision prompt in deterring sedentary behavior. Am. J. Health Promot. 1999, 13, 257-259. [CrossRef] [PubMed]

20. Soler, R.E.; Leeks, K.D.; Buchanan, L.R.; Brownson, R.C.; Heath, G.W.; Hopkins, D.H. Point-of-Decision Prompts to Increase Stair Use. Am. J. Prev. Med. 2010, 38, S292-S300. [CrossRef]

21. Fulton, J.E.; Frederick, G.M.; Paul, P.; Omura, J.D.; Carlson, S.A.; Dorn, J.M. Increasing Walking in the Hartsfield-Jackson Atlanta International Airport: The Walk to Fly Study. Am. J. Public Health 2017, 107, 1143-1149. [CrossRef]

22. Beckelman, T.; Sinclair-White, B.M.; McGurk, M.D.; Donohoe-Mather, C.; Vu, U.; Ching, L.K.; Pirkle, C.M.; Sentell, T.L.; Keliikoa, L.B. Encouraging Adults to Choose Healthy Now: A Hawai'i Convenience Store Intervention. J. Nutr. Educ. Behav. 2020, 52, 330-334. [CrossRef]

23. Papies, E.K.; Potjes, I.; Keesman, M.; Schwinghammer, S.; Van Koningsbruggen, G.M. Using health primes to reduce unhealthy snack purchases among overweight consumers in a grocery store. Int. J. Obes. 2013, 38, 597-602. [CrossRef]

24. Food Insight. 2013 Food and Health Survey. International Food Information Council Foundation. 2013. Available online: https://foodinsight.org/2013-food-and-health-survey (accessed on 22 June 2020).

25. Malochleb, M. Feeding the Gut Microbiome. IFT. 2020. Available online: https://www.ift.org/news-andpublications/food-technology-magazine/issues/2020/may/features/feeding-the-gut-microbiome (accessed on 22 June 2020).

26. Quagliani, D.; Felt-Gunderson, P. Closing America's Fiber Intake Gap. Am. J. Lifestyle Med. 2016, 11, 80-85. [CrossRef]

27. Redman, R. Study: Number of online grocery shoppers surges. Supermarket News. Updated [14 May 2019]. Available online: https://www.supermarketnews.com/online-retail/study-number-online-grocery-shopperssurges (accessed on 11 July 2020).

28. Olzenak, K.; French, S.; Sherwood, N.; Redden, J.P.; Harnack, L. How Online Grocery Stores Support Consumer Nutrition Information Needs. J. Nutr. Educ. Behav. 2020, 52, 952-957. [CrossRef]

29. International Food Information Council. National Voter Poll Evaluating Online Grocery Shopping. Gallup: Washington, DC. Updated [February 2018]. Available online: https://foodinsight.org/wp-content/uploads/ 2018/03/Online-Shopping-Habits.pdf (accessed on 14 October 2020).

30. WHO. WHO Strategic Communications Framework for Effective Communications. 2017. Available online: https://www.who.int/mediacentre/communication-framework.pdf (accessed on 11 July 2020).

31. Canva. "Home-Canva". Available online: https://www.canva.com/ (accessed on 11 November 2020).

32. Lusk, J.L. Effects of Cheap Talk on Consumer Willingness-to-Pay for Golden Rice. Am. J. Agric. Econ. 2003, 85, 840-856. [CrossRef]

33. R Core Team. R: A Language and Environment for Statistical Computing; R Foundation for Statistical Computing: Vienna, Austria, 2019; Available online: https://cran.r-project.org/ (accessed on 2 February 2019).

34. Allan, J.L.; McMinn, D.; Daly, M. A Bidirectional Relationship between Executive Function and Health Behavior: Evidence, Implications, and Future Directions. Front. Neurosci. 2016, 10, 386. [CrossRef] [PubMed]

35. Nelson, T.D.; Nelson, J.M.; Mason, W.A.; Tomaso, C.C.; Kozikowski, C.B.; Espy, K.A. Executive Control and Adolescent Health: Toward A Conceptual Framework. Adolesc. Res. Rev. 2018, 4, 31-43. [CrossRef] [PubMed]

36. Hare, T.A.; Camerer, C.F.; Rangel, A. Self-Control in Decision-Making Involves Modulation of the vmPFC valuation system. Science 2009, 324, 646-648. [CrossRef]

37. Hare, T.A.; Malmaud, J.; Rangel, A. Focusing Attention on the Health Aspects of Foods Changes Value Signals in vmPFC and Improves Dietary Choice. J. Neurosci. 2011, 31, 11077-11087. [CrossRef] [PubMed] 
38. Hallez, L.; Qutteina, Y.; Raedschelders, M.; Boen, F.; Smits, T. That's My Cue to Eat: A Systematic Review of the Persuasiveness of Front-of-Pack Cues on Food Packages for Children vs. Adults. Nutrients 2020, 12, 1062. [CrossRef]

39. Food Insight. Consumer Survey: COVID-19s Impact on Food Purchasing, Eating Behaviors and Perceptions of Food Safety. International Food Information Council. Updated (14 April 2020). Available online: https://foodinsight.org/consumer-survey-covid-19s-impact-on-food-purchasing/ (accessed on 11 July 2020).

40. Nielsen. FMI and Nielsen: 70\% of Consumers Will be Grocery Shopping Online by 2024. Updated (January 2018). Available online: https://www.nielsen.com/us/en/press-releases/2018/fmi-and-nielsen-online-groceryshopping-is-quickly-approaching-saturation (accessed on 1 July 2020).

41. Keeter, S. A Third of Americans Experienced High Levels of Psychological Distress during the Coronavirus Outbreak. Pew Research Center. Updated (May 2020). Available online: https://www.pewresearch.org/fact-tank/2020/05/07/a-third-of-americans-experienced-high-levelsof-psychological-distress-during-the-coronavirus-outbreak/ (accessed on 15 June 2020).

42. Creswell, J. I Just Need the Comfort': Processed Foods Make a Pandemic Comeback. The New York Times, 7 April 2020. Available online: https://www.nytimes.com/2020/04/07/business/coronavirus-processed-foods. html (accessed on 15 April 2020).

Publisher's Note: MDPI stays neutral with regard to jurisdictional claims in published maps and institutional affiliations.

(C) 2020 by the authors. Licensee MDPI, Basel, Switzerland. This article is an open access article distributed under the terms and conditions of the Creative Commons Attribution (CC BY) license (http://creativecommons.org/licenses/by/4.0/). 